\title{
Endothelial mediators of 17ß-estradiol-induced coronary vasodilation in the isolated rat heart
}

R.L. Santos, G.R. Abreu, N.S. Bissoli and M.R. Moysés

\author{
Departamento de Ciências Fisiológicas, Centro Biomédico, \\ Universidade Federal do Espírito Santo, Vitória, ES, Brasil
}

\begin{abstract}
Correspondence

M.R. Moysés

Departamento de Ciências Fisiológicas

Centro Biomédico, UFES

Av. Marechal Campos, 1468

29042-755 Vitória, ES

Brasil

Fax: $+55-27-3335-7330$

E-mail: mrmoyses@npd.ufes.br

Research supported by CNPq.

Received June 2, 2003

Accepted January 7, 2004

The present study was designed to determine relaxation in response to 17ß-estradiol by isolated perfused hearts from intact normotensive male and female rats as well as the contribution of endothelium and its relaxing factors to this action. Baseline coronary perfusion pressure was determined and the vasoactive effects of 173 -estradiol $(10 \mu \mathrm{M})$ were assessed by in bolus administration before and after endothelium denudation by infusion of $0.25 \mu \mathrm{M}$ sodium deoxycholate or perfusion with $100 \mu \mathrm{M}$ L-NAME, $2.8 \mu \mathrm{M}$ indomethacin, $0.75 \mu \mathrm{M}$ clotrimazole, $100 \mu \mathrm{M}$ L-NAME plus $2.8 \mu \mathrm{M}$ indomethacin, and $100 \mu \mathrm{M}$ L-NAME plus $0.75 \mu \mathrm{M}$ clotrimazole. Baseline coronary perfusion pressure differed significantly between males $(84 \pm 2 \mathrm{mmHg}, \mathrm{N}=61)$ and females $(102 \pm 2 \mathrm{mmHg}, \mathrm{N}=61)$. Bolus injection of $10 \mu \mathrm{M} 17 ß-$ estradiol elicited a transient relaxing response in all groups, which was greater in coronary beds from females. For both sexes, the relaxing response to $17 ß$-estradiol was at least in part endothelium-dependent. In the presence of the nitric oxide synthase inhibitor L-NAME, the relaxing response to $17 ß$-estradiol was reduced only in females. Nevertheless, in the presence of indomethacin, a cyclooxygenase inhibitor, or clotrimazole, a cytochrome P450 inhibitor, the 17ßestradiol response was significantly reduced in both groups. In addition, combined treatment with L-NAME plus indomethacin or L-NAME plus clotrimazole also reduced the 17ß-estradiol response in both groups. These results indicate the importance of prostacyclin and endothelium-derived hyperpolarizing factor in the relaxing response to $17 ß$-estradiol. 17ß-estradiol-induced relaxation may play an important role in the regulation of coronary tone and this may be one of the reasons why estrogen replacement therapy reduces the risk of coronary heart disease in postmenopausal women.
\end{abstract}

\section{Introduction}

Premenopausal women with normal estrogen levels rarely manifest coronary disease. In addition, the administration of exogenous estrogens to healthy postmenopausal women markedly reduces the incidence of
Key words

- Estrogen

- Vasodilation

- Endothelium-derived

relaxing factors

- Coronary arteries 
data have suggested that the direct actions of estrogen on blood vessels contribute substantially to the cardiovascular protective effects of estrogen (4,5). For instance, a considerable body of evidence suggests that an important protective effect of estrogen is due to the potentiation of the actions of endothelium-derived relaxing factors $(6,7)$. The ability of estrogen to increase the bioavailability of the vasodilator, anti-aggregating and anti-proliferative substance nitric oxide (NO) is a topic of intense current investigation (8). NO is formed in vascular endothelial cells lining blood vessels through the activity of constitutive endothelial NO synthase (eNOS). Expression of the gene encoding eNOS is increased in endothelial cells exposed to estrogen $(9,10)$. In addition, estrogen might modulate NO synthesis through its direct antioxidant effects (11) and by regulating the expression of genes encoding essential co-factor or enzymes that increase eNOS activity by post-translational modification (12). Enhancement of endothelial function by estrogen is potentiated by a concomitant rise in the synthesis of prostacyclin $\left(\mathrm{PGI}_{2}\right)$ through the activation of the gene encoding cyclooxygenase in endothelial cells (13). Recently, some studies $(14,15)$ have demonstrated a relationship between estrogen and endothelium-derived hyperpolarizing factor (EDHF). The elucidation of the chemical nature and properties of EDHF has recently received a lot of attention. It is now clear that several EDHFs specific for different species are likely to be present in vascular beds. However, little is known about the control and regulation of EDHF synthesis and/or release, mainly because the structure of EDHF has not yet been determined. In addition, almost nothing is known about the relationship between estrogen and EDHF. Additionally, estrogen can enhance calcium channel-blocking agents (16). Estrogen-induced relaxation may play an important role in the regulation of coronary tone and this may be one of the explanations of why estro- gen replacement therapy reduces the risk of coronary heart disease in postmenopausal women (17). Nevertheless, the mechanisms underlying this action are unknown (18). In addition, only few studies have addressed the actions of estrogen on the coronary vascular bed. Thus, the aim of the present study was to assess the relative contribution of endothelium and its relaxation factors (NO, $\mathrm{PGI}_{2}$ and EDHF) to the relaxing response to $17 ß$-estradiol in isolated perfused heart from intact female and male rats.

\section{Material and Methods}

The investigation was conducted in compliance with the Guide for Biomedical Research, as stated by the Brazilian Societies of Experimental Biology (FeSBE), and with the guiding principles of other physiological Societies for research involving animals. The experiments were performed on isolated perfused hearts from male and female Wistar rats (200-300 g). The rats were anesthetized with chloral hydrate $(40 \mathrm{mg} / \mathrm{kg}$, ip) and injected $s c$ with heparin (100 units/kg). Fifteen minutes after heparin injection, the rats were killed and the hearts were immediately excised and perfused at a constant flow. The studies on the coronary vascular bed were performed on whole hearts using a Langendorff preparation for perfused isolated hearts (19). Briefly, using a Langendorff apparatus (Hugo Sachs Electronics, March-Hugstetten, Germany), the isolated hearts were perfused with modified Krebs solution containing 120 $\mathrm{mM} \mathrm{NaCl}, 1.26 \mathrm{mM} \mathrm{CaCl} 2 \mathrm{H}_{2} \mathrm{O}, 5.4 \mathrm{mM}$ $\mathrm{KCl}, 2.5 \mathrm{mM} \mathrm{MgSO}_{4} 7 \mathrm{H}_{2} \mathrm{O}, 2 \mathrm{mM}$ $\mathrm{NaH}_{2} \mathrm{PO}_{4} \mathrm{H}_{2} \mathrm{O}, 27 \mathrm{mM} \mathrm{NaHCO}, 1.2 \mathrm{mM}$ $\mathrm{Na}_{2} \mathrm{SO}_{4}, 0.03 \mathrm{mM}$ EDTA, and $11.0 \mathrm{mM}$ glucose, equilibrated with a $95 \%$ oxygen and $5 \%$ carbon dioxide mixture at a controlled pressure of $100 \mathrm{mmHg}$ to give a $\mathrm{pH}$ of 7.4, perfused at a rate of $10 \mathrm{ml} / \mathrm{min}$ with a peristaltic pump (MS-Reglo 4 channels, Hugo Sachs Electronics), and kept at $37^{\circ} \mathrm{C}$. A fluidfilled balloon was introduced into the left 
ventricle through a steel cannula with a latex balloon and connected to a TPS-2 Statham transducer (Incor, São Paulo, SP, Brazil) to measure the isovolumetric cardiac force. The balloon was pressurized with a spindle syringe until it reached a preload of $10 \mathrm{mmHg}$.

Coronary perfusion pressure (CPP) was monitored with a TPS-2 Statham transducer connected to a sidearm of the aortic perfusion catheter. Once the preparation was stabilized, baseline CPP was measured after about $40 \mathrm{~min}$ and the vasoactive effects of 10 $\mu \mathrm{M} 173$-estradiol were assessed by in bolus administration before and after endothelium denudation by infusion of sodium deoxycholate $(0.25 \mu \mathrm{M}$ deoxycholic acid $)$ for 10 min or by perfusion with $100 \mu \mathrm{M} \mathrm{N}{ }^{\omega_{-}}$-nitroL-arginine methyl ester (L-NAME), $2.8 \mu \mathrm{M}$ indomethacin, $0.75 \mu \mathrm{M}$ clotrimazole, 100 $\mu \mathrm{M}$ L-NAME plus $2.8 \mu \mathrm{M}$ indomethacin, and $100 \mu \mathrm{M}$ L-NAME plus $0.75 \mu \mathrm{M}$ clotrimazole. All inhibitors were perfused for at least 20 min until the bolus injection of 17ßestradiol was repeated.

\section{Results}

There was a statistically significant difference in baseline CPP between female ( $\mathrm{N}$ $=61)$ and male $(\mathrm{N}=61)$ hearts $(102 \pm 2$ vs 84 $\pm 2 \mathrm{mmHg}$, respectively). Bolus injection of $10 \mu \mathrm{M} 173$-estradiol elicited a transient relaxing response in both groups. There were differences in 17ß-estradiol-induced relaxation between female and male animals before endothelium denudation $(-15 \pm 2 v s-11$ $\pm 2 \%$, respectively). The response to 173 estradiol was significantly attenuated after endothelium removal in both groups (Figure 1B), but was not blocked, thus indicating an indirect (endothelium-mediated) mechanism as well as a direct action of $17 \AA$-estradiol on vascular smooth muscle.

In the spontaneously beating heart employed here, a bolus injection of bradykinin elicited a reduction in CPP. Since bradykinin exerts coronary vasodilation via an endothe- lium-dependent mechanism, we examined the vasodilatory response of the isolated heart to bradykinin before and after treatment with $0.25 \mu \mathrm{M}$ deoxycholic acid to confirm endothelium removal. Treatment with sodium deoxycholate reduced significantly the vasodilatory response to $0.5 \mu \mathrm{M}$ bradykinin in both the female $(-15 \pm 2$ to $-4 \pm 1 \%, \mathrm{~N}=8)$ and male $(-11 \pm 2$ to $-3 \pm 1 \%, \mathrm{~N}=8)$ groups, while the vasodilatory response to $0.1 \mathrm{mM}$ sodium nitrite (an NO donor) remained unchanged in both groups. These results suggest that after treatment with deoxycholic acid the ability of coronary endothelial cells to produce relaxing factors is reduced, whereas the ability of vascular smooth muscle to respond to sodium nitrite remains unchanged. The concentration of deoxycholic acid used here is suitable for the removal of endothelial cells, as shown in a previous study by our group (20).

In presence of the NOS inhibitor LNAME $(100 \mu \mathrm{M})$ the dilating response to 17ß-estradiol was reduced only in the female group $(-15 \pm 2$ to $-10 \pm 1 \%$; Figure $1 \mathrm{C})$.
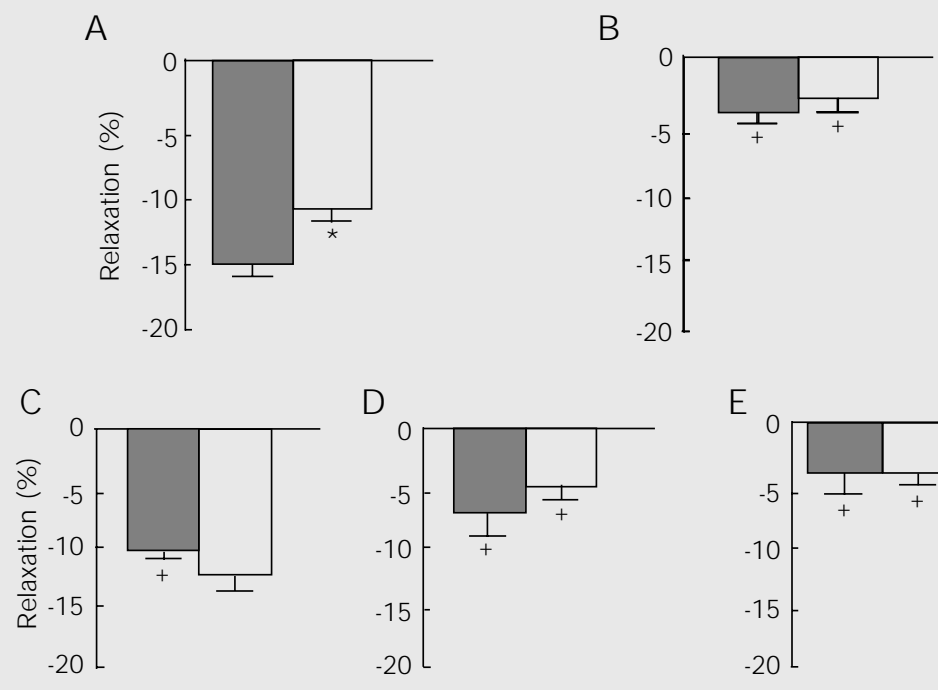

D
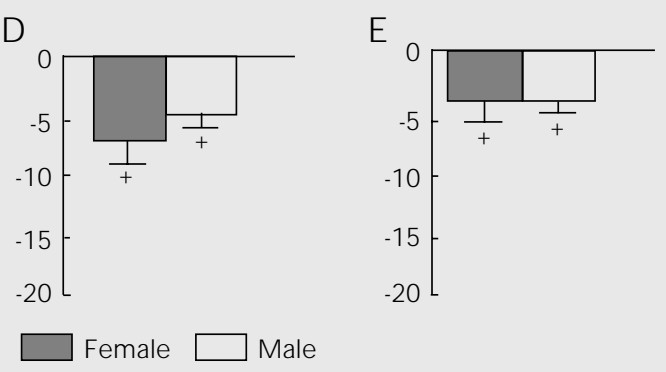

Figure 1. Relaxing response to $17 ß$-estradiol in the coronary vascular bed of female and male animals before $(A$, control, $N=10)$ and after endothelium removal $(B, N=10)$ or perfusion with L-NAME $(C, N=11)$, indomethacin $(D, N=11)$ or clotrimazole $(E, N=9)$. Data are reported as means \pm SEM. $* P<0.01$ compared to females before the different treatments (unpaired Student t-test). $+\mathrm{P}<0.01$ compared to the same group under control conditions (A) (paired Student t-test). 
Figure 2. Relaxing response to 17 ß-estradiol in coronary vascular bed from female and male animals before and after perfusion with L-NAME plus indomethacin (L-NAME + Indo, $\mathrm{N}=$ 11) or L-NAME plus clotrimazole (L-NAME + Clot, $\mathrm{N}=9$ ). Data are reported as means $\pm \mathrm{SEM}$. $* \mathrm{P}<$ 0.01 compared to female before the different treatments (unpaired Student t-test). ${ }^{+} \mathrm{P}<0.01$ compared to the same group before the different treatments (paired Student t-test).
Nevertheless, in the presence of indomethacin (Figure 1D) or clotrimazole (Figure 1E) the response to 173 -estradiol was significantly reduced in both groups. In addition, the combined treatment with L-NAME plus indomethacin or L-NAME plus clotrimazole (Figure 2) also reduced the response to 17ß-

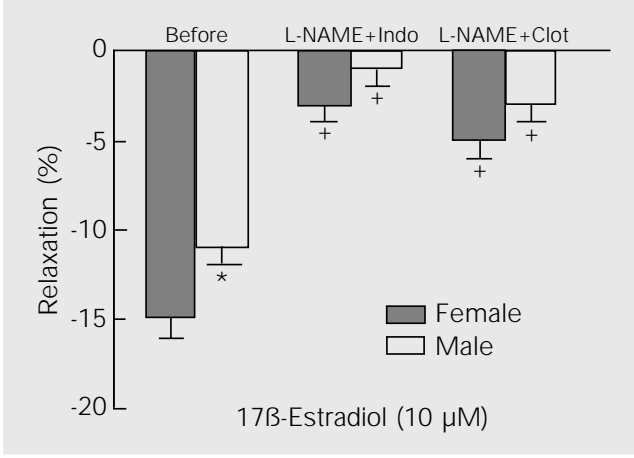

Table 1. Coronary perfusion pressure of isolated hearts from female and male rats before and after endothelium denudation by infusion of sodium deoxycholate $(0.25 \mu \mathrm{M})$ for $10 \mathrm{~min}$.

\begin{tabular}{lcc} 
Group & \multicolumn{2}{c}{ Coronary perfusion pressure $(\mathrm{mmHg})$} \\
\cline { 2 - 3 } & $\begin{array}{c}\text { Before endothelium } \\
\text { denudation }\end{array}$ & $\begin{array}{c}\text { After endothelium } \\
\text { denudation }\end{array}$ \\
\hline Females & $95 \pm 4$ & $161 \pm 11^{*}$ \\
Males & $79 \pm 3$ & $134 \pm 8^{*}$
\end{tabular}

Data are reported as means $\pm \mathrm{SEM}$ in $\mathrm{mmHg}$ for 10 experiments in each group.

$* \mathrm{P}<0.01$ compared to the same group before endothelium denudation (paired Student t-test).

Table 2. Coronary perfusion pressure of isolated hearts from female and male rats before and after perfusion with $100 \mu \mathrm{M}$ L-NAME, $2.8 \mu \mathrm{M}$ indomethacin or $0.75 \mu \mathrm{M}$ clotrimazole.

\begin{tabular}{|c|c|c|c|c|c|c|c|c|c|}
\hline \multirow[t]{2}{*}{ Group } & \multicolumn{3}{|c|}{ L-NAME } & \multicolumn{3}{|c|}{ Indomethacin } & \multicolumn{3}{|c|}{ Clotrimazole } \\
\hline & $N$ & Before & After & $N$ & Before & After & $\mathrm{N}$ & Before & After \\
\hline Female & 11 & $105 \pm 6$ & $174 \pm 8^{*}$ & 11 & $104 \pm 4$ & $127 \pm 6^{*}$ & 9 & $103 \pm 6$ & $105 \pm 6$ \\
\hline Males & 11 & $87 \pm 4$ & $141 \pm 8^{*}$ & 11 & $86 \pm 4$ & $105 \pm 5^{*}$ & 9 & $72 \pm 2$ & $75 \pm 3$ \\
\hline
\end{tabular}

Data are reported as means \pm SEM in $\mathrm{mmHg} . \mathrm{N}=$ number of experiments. $* \mathrm{P}<0.05$ compared to the same group before perfusion with different inhibitors (paired Student t-test).

estradiol in both groups. These results indicate the importance of $\mathrm{PGI}_{2}$ and EDHF in the dilating response to $17 ß$-estradiol. Endothelium removal elicited a significant increase in CPP (Table 1), showing the important role of endothelium as a regulator of coronary tone. The significant contribution of basal $\mathrm{NO}$ and $\mathrm{PGI}_{2}$ release to the maintenance of coronary tone is illustrated by the marked increase in CPP observed following inhibition of $\mathrm{NO}$ synthesis or $\mathrm{PGI}_{2}$ synthesis (Table 2). However, inhibition of EDHF (by inhibition of cytochrome P450) had no effect on CPP (Table 2).

\section{Discussion}

The present study was carried out on isolated hearts with intact whole coronary vascular beds in basal conditions. We found that basal CPP was significantly higher in hearts from control female rats than in those from control male rats. This sex difference in basal CPP seems to be related to the presence of ovarian sex hormones (20). With respect to the high level of CPP observed in the female group, it is known that estrogen may have indirect effects on the cardiovascular system, e.g., through an interaction with the renin-angiotensin system. This system has been associated with intramural renin-like enzyme and angiotensinogen levels in several organs and systems, including the coronary circulation (21). 17ß-estradiol increases the synthesis of hepatic angiotensinogen, raising the content of angiotensin II and sodium, with a consequent increase in arterial pressure (22). Further experiments are necessary to elucidate the basis for the ovarian sex hormone-dependent elevated CPP and whether this elevation has a role in the cardioprotective effect of estrogen observed in female rats. Even though we had found differences in basal CPP between male and female rats, our main aim was to study the relaxing response to 173 -estradiol in isolated perfused hearts from intact male and 
female rats and the contribution of the endothelium and its relaxing factors $\left(\mathrm{NO}, \mathrm{PGI}_{2}\right.$ and EDHF) to this action. Bolus injection of $10 \mu \mathrm{M} 173$-estradiol elicited a transient relaxing response approximately $30 \mathrm{~s}$ after the injection in both groups. This rapid effect of estrogen on the blood vessel wall is believed to occur without any changes in gene expression, probably as a result of "nongenomic" mechanisms (23).

There were differences in 17B-estradiolinduced relaxation between female and male control animals. Our data demonstrate that in the rat coronary microcirculation the acute relaxing response to $17 ß$-estradiol is, at least in part, endothelium-dependent, but this hormone may also have a direct action on vascular smooth muscle which is observed by higher 17ß-estradiol concentrations ( $\cong 10$ $\mu \mathrm{M})$. This mechanism has been suggested to occur by a) hyperpolarization of vascular smooth muscle mediated by an increase in outward potassium currents (24), or b) a competitive inhibition of $\mathrm{Ca}^{2+}$ entry through L-type calcium ion channels (25-27). Our experiments failed to suggest a preferential endothelium-independent mechanism as a basis for vasodilation.

In coronary arteries, 17ß-estradiol stimulates the release of three distinct endothelium-derived relaxing compounds: $\mathrm{NO}, \mathrm{PGI}_{2}$ and EDHF. The contribution of each of these factors to endothelium-dependent vasodilation varies across vascular beds and also according to what agent is used to stimulate the endothelium. In general, the endothelium predominantly releases $\mathrm{NO}$ in large arteries (28) such as carotid arteries (29), while the contribution of EDHF is more important in smaller resistance arteries (30) such as the mesenteric arteries (31), and arterioles (32). The involvement of prostanoid (mainly prostacyclin) in the regulation of vascular tone has not been widely reported and is often overlooked due to experimental designs in which cyclooxygenase blockers were present since the onset of experimentation. There- fore, the role of prostanoids in regulating vessels of different size awaits elucidation.

The present results demonstrate that treatment with L-NAME reduced the relaxing response to $17 ß$-estradiol only in the female group. However, the relaxing response to $17 ß$-estradiol was significantly reduced in both groups after cyclooxygenase blockade, an effect that might be explained by a reduced formation of vasodilating prostanoid, such as $\mathrm{PGI}_{2}$. The strong inhibitory effect of clotrimazole suggests that a cytochrome P450-derived metabolite of arachidonic acid released from the endothelium displays the characteristics of EDHF in the coronary microcirculation. The results of the present study demonstrate for the first time that EDHF participates in the acute relaxing response to $17 ß$-estradiol in the isolated perfused heart. In addition, in the presence of L-NAME plus indomethacin or L-NAME plus clotrimazole, the response to 173 -estradiol was significantly reduced in both groups, indicating the importance of $\mathrm{PGI}_{2}$ and EDHF in the dilating response to 173 -estradiol. Although $\mathrm{NO} / \mathrm{PGI}_{2}$-independent agonist-induced vasodilatation is referred to as EDHF release (33), it is still unclear to what extent EDHF contributes to the vasodilating response when the synthesis of $\mathrm{NO}$ and $\mathrm{PGI}_{2}$ is not inhibited. In our model of coronary microcirculation, the 17ß-estradiol-induced dilatation was attenuated by clotrimazole alone. This finding suggests that the EDHF-induced dilation is not simply a response observed following inhibition of the synthesis of the other dilatory autocoids, but represents a substantial constitutive component of the relaxing response to $17 ß$-estradiol in the coronary microcirculation under physiological conditions.

The role of the endothelium in the control of coronary tone is illustrated by the significant increase in CPP after endothelium denudation. The contribution of basal and shear stress-dependent NO release to the maintenance of coronary tone is illustrated 
by the marked increase in CPP observed following inhibition of NO synthesis. Cyclooxygenase inhibition also increased CPP, suggesting that the basal release of cyclooxygenase products, i.e., $\mathrm{PGI}_{2}$, participates in the maintenance of coronary tone. Nonetheless, cytochrome $\mathrm{P} 450$ inhibition was without effect on CPP under control conditions, suggesting that the basal release of cytochrome $\mathrm{P} 450$ products, i.e., EDHF, is too low to influence significantly the tone of the coronary arteries.

Therefore, we conclude that the relaxing effect of 17ß-estradiol on the rat coronary artery is mediated by an indirect endothelium-mediated mechanism as well as by a direct action on vascular smooth muscle. Although 17ß-estradiol stimulates the release of three distinct endothelium-derived relaxing compounds (NO, $\mathrm{PGI}_{2}$ and EDHF), $\mathrm{PGI}_{2}$ and EDHF may have the most important role as mediators of the relaxing response to 17ß-estradiol. In addition, the significant contribution of basal $\mathrm{NO}$ and $\mathrm{PGI}_{2}$ release is demonstrated by the marked increase in coronary perfusion pressure.

\section{Acknowledgments}

The authors thank Elisardo C. Vasquez, Ph.D., for a critical review and Marco Franco for revising the English text.

\section{References}

1. Stampfer MJ , Colditz GA, Willett WC, Manson J E, Rosner B, Speizer FE \& Hennekens CH (1991). Postmenopausal estrogen therapy and cardiovascular disease. New England J ournal of Medicine, 325: 756-762.

2. Barret-Connor E \& Bush TL (1991). Estrogen and coronary heart disease in women. Journal of the American Medical Association, 256: 1861-1867.

3. Grady D, Rubin SM, Petiti DB, Fox CS, Black D, Ettinger B, Emster YL \& Cumings SR (1992). Hormone therapy to prevent disease and prolong life in postmenopausal women. Annals of Internal Medicine, 117: 1016-1037.

4. Mendelsohn ME \& Karas RH (1994). Estrogen and the blood vessel wall. Current Opinion in Cardiology, 9: 619-626.

5. Farhat MY, Lavigne MC \& Ramwell PW (1996). The vascular protective effects of estrogen. FASEB J ournal, 10: 615-624.

6. Hayashi T, Fukuto J M, Ignarro LJ \& Chaudhuri G (1992). Basal release of nitric oxide from aortic rings is greater in female rabbits than in male rabbits: implications for atherosclerosis. Proceedings of the National Academy of Sciences, USA, 89: 11259-11263.

7. Gisclard V, Miller VM \& Vanhoutte PM (1988). Effect of 17ß-estradiol on endothelium-dependent responses in the rabbit. J ournal of Pharmacology and Experimental Therapeutics, 244: 19-22.

8. Mendelsohn ME (2000). Nongenomic, estrogen receptor-mediated activation of endothelial nitric oxide synthase. How does it work? What does it mean? Circulation Research, 87: 677-682.

9. Hayashi T, Yamada K, Esaki T, Kuzuya M, Satake S, Ishikawa T, Hidaka H \& Iguchi A (1995). Estrogen increases endothelial nitric oxide by a receptor-mediated system. Biochemical and Biophysical Research Communications, 214: 847-855.

10. Hishikawa K, Nakani T, Marumo T, Suzuki H, Kato R \& Sanuta T (1995). Up-regulation of nitric oxide synthase by estradiol in human aortic endothelial cells. FEBS Letters, 360: 291-293.

11. Haliwell B \& Grootveld M (1987). The measurement of free radical reactions in humans. Some thoughts for future experimentations.
FEBS Letters, 213: 9-16.

12. Kauser K \& Rubanyi GM (1997). Potential cellular signalling mechanisms mediating upregulation of endothelial nitric oxide production by estrogen. J ournal of Vascular Research, 34: 229-236.

13. J un SS, Chen Z, Pace MC \& Shaul PW (1998). Estrogen upregulates cyclo-oxygenase-1 gene expression in ovine fetal pulmonary artery endothelium. J oumal of Clinical Investigation, 102: 176-183.

14. Golding EM \& Kepler TE (2001). Role of estrogen in modulating EDHF-mediated dilations in the female rat middle cerebral artery. American J ournal of Physiology, 280: H2417-H2423.

15. Wu Y, Huang A, Sun D, Falck J R, Koller A \& Kaley G (2001). Gender specific compensation for the lack of nitric oxide in the mediation of flow-induced arteriolar dilation. American J ournal of Physiology, 280: H2456-H2461.

16. Collins $P$, Rosano GMC, J iang C, Lindsay D, Sarrel PM \& PooleWilson PA (1993). Cardiovascular protection by oestrogen - a calcium antagonist effect? Lancet, 341: 1264-1265.

17. J iang C, Sarrel PM, Lindsay DC, Poole-Wilson PA \& Collins P (1991). Endothelium-independent relaxation of rabbit coronary artery by 17ß-oestradiol in vitro. British J oumal of Pharmacology, 104: 10331037.

18. Stevenson J C (2000). Cardiovascular effects of oestrogens. J ournal of Steroid Biochemistry and Molecular Biology, 74: 387-393.

19. Döring HJ (1990). The isolated perfused heart according to Langendorff technique - function - application. Physiologia Bohemoslovaca, 39: 482-496.

20. Moysés MR, Barker LA \& Cabral AM (2001). Sex hormone modulation of serotonin-induced coronary vasodilation in isolated heart. Brazilian J ournal of Medical and Biological Research, 34: 949-958.

21. Dzau VJ (1988). Circulating versus local renin-angiotensin system in cardiovascular homeostasis. Circulation, 77 (Suppl I): 4-13.

22. Oelskers WHK (1996). Effects of estrogens and progestogens on the renin-aldosterone system and blood pressure. Steroids, 61: 166-171. 
23. Mendelsohn ME \& Karas RH (1999). Mechanisms of disease: the protective effects of estrogen on the cardiovascular system. New England J ournal of Medicine, 340: 1801-1811.

24. Valverde MA, Rojas P, Amigo J , Cosmelli D, Patricio O, Bahamonde MI, Mann GE, Vergara C \& Latorre R (1999). Acute activation of maxi-K channels (hSlo) by estradiol binding to the $B$ subunit. Science, 285: 1929-1931.

25. Nakajima T, Kitazawa T, Hamada E, Hazama H, Omata M \& Kurachi Y (1995). 17ß-Estradiol inhibits the voltage-dependent L-type $\mathrm{Ca}^{2+}$ currents in aortic smooth muscle cells. European J oumal of Pharmacology, 294: 625-635.

26. J ohnson BD, Zheng W, Korach KS, Sheuer T, Catterall WA \& Rubanyi GM (1997). Increased expression of the cardiac L-type calcium channel in estrogen receptor-deficient mice. J ournal of General Physiology, 110: 135-140.

27. Ruelmann DO, Steinert J R, Valverde MA, Jacob R \& Mann GE (1998). Environmental estrogenic pollutants induce acute vascular relaxation by inhibiting L-type $\mathrm{Ca}^{2+}$ channels in smooth muscle cells. FASEB J ournal, 12: 613-619.

28. Nagao T, Illiano S \& Vanhoutte PM (1992). Heterogenous distribu- tion of endothelium-dependent relaxation resistant to $\mathrm{N}^{\mathrm{G}}$-nitro-Larginine in rats. American J oumal of Physiology, 263: H1090-H1094.

29. Cohen RA, Plane F, Najibi S, Huk I, Malinski T \& Garland CJ (1997). Nitric oxide is the mediator of both endothelium-dependent relaxation and hyperpolarization of the rabbit carotid artery. Proceedings of the National Academy Sciences, USA, 94: 4193-4198.

30. Garland CJ , Plane F, Kemp BK \& Cocks TM (1995). Endotheliumdependent hyperpolarization: a role in the control of vascular tone. Trends in Pharmacological Sciences, 16: 23-30.

31. Shimokawa H, Yasutake H, Fujii K et al. (1996). The importance of the hyperpolarizing mechanism increases as the vessel size decreases in endothelium-dependent relaxations in rat mesenteric circulation. J ournal of Cardiovascular Pharmacology, 28: 703-711.

32. Huang A, Wu Y, Sun D, Koller A \& Kaley G (2001). Effect of estrogen on flow-induced dilation in NO deficiency: role of prostaglandins and EDHF. J ournal of Applied Physiology, 9: 2561-2566.

33. Nagao T \& Vanhoutte PM (1992). Hyperpolarization as a mechanism for endothelium-dependent relaxation in the porcine coronary artery. J oumal of Physiology, 445: 335-367. 